\title{
Divergências teóricas, divergências políticas: a crítica da USP aos "estudos de comunidades"1
}

\author{
Luiz Carlos Jackson
}

\begin{abstract}
resumo Neste artigo o autor esmiuça a crítica uspiana, realizada entre os anos 1940-1960, em relação aos estudos de comunidade, principalmente, aqueles vinculados à Escola Livre de Sociologia e Política.
\end{abstract}

palavras-chave Estudos de comunidade. Escola Livre de Sociologia e Política. Universidade de São Paulo. História das Ciências Sociais.

Os "estudos de comunidades" foram recusados pelos sociólogos da USP com termos muito próximos aos utilizados por Caio Prado Jr. em resenha ao livro Cunha, de Emílio Willems, publicada em Fundamentos (Prado Jr, 1948), revista de cultura vinculada ao PCB. $O$ fato é muito significativo para constatar-se a imbricação profunda entre ciência e política (aprofundada com o golpe de 1964) que caracterizou os decênios de institucionalização das ciências sociais em São Paulo, apesar da separação crescente entre tais domínios inerente a esse processo.

Em 1941, Emílio Willems assumiu a recém criada cadeira de Antropologia na Faculdade de Filosofia Ciências e Letras da Universidade de São Paulo, no mesmo ano em que foi convidado por Donald Pierson para lecionar na Escola Livre de Sociologia e Política, em sua Divisão de Estudos Pós-graduados. Neste programa, vários alunos da USP, entre os quais Florestan Fernandes e Gioconda Mussolini, obtiveram o mestrado na década de 1940, justamente quando o antropólogo alemão esfor- çava-se, numa espécie de "missão ecumênica", para reunir as duas instituiçôes na construção das ciências sociais em São Paulo.

Tal objetivo foi perseguido também na direção de Sociologia ${ }^{2}$, primeiro periódico especializado em ciências sociais editado no Brasil. Neste (v.10, n.2), em 1948, Willems publicou o "Symposium sobre classes sociais"3, no qual Florestan (Fernandes, 1948) escreveu "A análise sociológica das classes sociais", em oposição clara aos artigos assinados por Willems e Pierson no mesmo número.

O confronto explicitaria a disputa entre ELSP e USP e as dificuldades inerentes ao "projeto ecumênico" de Willems. Se o tom acadêmico do debate disfarçava a tomada de posição de Florestan Fernandes em favor da crítica politizada de Caio Prado Jr. a Cunha, marcava claramente a oposição entre as diferentes concepções de ensino e pesquisa que caracterizavam as instituiçóes. $\mathrm{Na}$ primeira, prevalecia a ênfase na pesquisa empírica - etapa indispensável à generalização teórica na visão de Pierson (compartilhada por Willems) -, assim como no ensino "verdadeiramente científico", isto é, centrado na análise dos processos sociais efetivos e não na história das ideias sociológicas, esta considerada característica dos períodos pré-científicos da disciplina. Na USP, comparativamente, a pesquisa dependeria, nos termos de Willems, ao caracterizar sua própria formação europeia, mais da "iniciativa do estudante" do que de uma orientação sistemática forneci- 
da pelos professores. Seria, portanto, resultante da teoria, esta o cerne do ensino, baseado na discussão dos clássicos. Caricaturando, tenderiam (aos olhos dos rivais) à "pura descrição" e à "especulação".

Criticando os "estudos de comunidade", Florestan Fernandes recusava o empirismo e a ênfase nas diferenças culturais, que desviariam o observador do processo decisivo ao desenvolvimento brasileiro - a formação da sociedade de classes -, e defendia com toda força a abordagem sociológica, fundamentada na tradição teórica da disciplina, fazendo no final uma provocação à sociologia americana, ao associar a interpretação culturalista da estratificação social às "condiçôes de existência social nos Estados Unidos, onde as distinçôes de classes eram menos pronunciadas e cristalizadas do que nas sociedades europeias" (Fernandes, 1948, p. 112), repondo com certa ironia a dimensão política da crítica de Caio Prado Jr., que apontara o caráter reacionário de tais análises.

A realização dos "estudos de comunidades" associou-se a dois contextos acadêmicos específicos. O primeiro, centralizado na ELSP, teve Emílio Willems e Donald Pierson como mentores. O segundo resultou do acordo firmado entre o estado da Bahia e a Columbia University e foi coordenado por Charles Wagley e Thales de Azevedo ${ }^{4}$.

Pierson introduziu no meio acadêmico paulista as técnicas de pesquisa desenvolvidas pela escola sociológica de Chicago, que orientaram os "estudos de comunidades" no primeiro caso, financiados por fundaçóes norte-americanas, principalmente a Smithsonian Institution. Os textos de Oracy Nogueira, "Os estudos de comunidades no Brasil”, e de Charles Wagley, "Estudos de comunidades no Brasil sob perspectiva nacional", são úteis para apreendermos os objetivos e características gerais desses trabalhos, formulados por representantes de cada um dos programas. Segundo Wagley, estariam referidos a "uma cultura local, a uma unidade espacialmente delimitada, parte integrante de uma sociedade maior e mais complexa, e [teriam] empregado em sua maioria, métodos etnográficos" (Wagley, 1954, p. 3). Como referência fundamental, o antropólogo americano apontava então o estudo de Robert e Helen Lynd sobre Middletown, publicado em 1929, ao qual devemos acrescentar como referência decisiva para as pesquisas feitas no Brasil o livro de Redfield sobre Yucatan no México (Mussolini, 1955). Redfield fora professor de Donald Pierson em Chicago e teria influenciado a decisão da Smithsonian Institution de financiar projetos de pesquisa no Brasil. Os primeiros trabalhos aqui realizados, seguindo o levantamento de Wagley, seriam: Cunha: tradiçâo e transição numa comunidade rural do Brasil (Willems, 1947), Evolução da Estrutura Social de Guaratinguetá num periodo de trezentos anos (Lucila Herrmann, 1948), Cruz das Almas (Pierson, 1952), Buzio's Island (Willems; Mussolini, 1952) e Amazon Town (Wagley, 1953).

$\mathrm{O}$ traço comum aos estudos seria, segundo Wagley, a preocupaçáo com os problemas de mudança social e cultural, para ele extremamente significativos para o Brasil de então. No restante do texto, o autor esboça um quadro de referências para trabalhos futuros, discriminando regióes e subculturas no Brasil, mas antes afirma claramente a pretensão dos "estudos de comunidade":

Está implícita neste trabalho a hipótese de que, a despeito da diversidade de problemas que tem motivado pesquisas em comunidades brasileiras (e que as continuarão motivando), cada estudo feito ou por fazer contribuirá significativamente para um objetivo de longo alcance - o conhecimento empírico da cultura nacional brasileira (Wagley, 1954, grifos meus).

As pesquisas realizadas constituíram, para Oracy Nogueira, 
verdadeiro movimento intelectual, o mais vigoroso, até o momento, na história da pesquisa sociológica no país e, ao que tudo indica, com tendência a absorver uma parte cada vez mais considerável do interesse, da energia e dos recursos com que contarem os especialistas, que no futuro imediato, se empenharem no levantamento de dados sistemáticos para o conhecimento da realidade nacional (Nogueira, 1955).

Oracy Nogueira apontava ainda como contribuição futura, "à medida que [os estudos] se multipliquem", fornecer "um complemento e, em certa medida um corretivo aos estudos de caráter analítico" (idem, p. 98), deixando entrever o clima pouco favorável que marcou a recepção dos "estudos de comunidades", a começar por Caio Prado Jr.

Ao resenhar Cunha (1947), Caio Prado Jr. recusava o esforço de Emílio Willems em função da inadequação do método:

É a impressão que se tem ao terminar a leitura do livro, pois ela não leva realmente a nada, náo oferecendo outro resultado concreto que uma coleção de fatos dispersos e sem suficiente articulação num conjunto coerente e cientificamente sistematizado (Prado Jr, 1948, p. 24).

A pretensão de objetividade não justificaria o empirismo empobrecedor. Faltando uma ideia diretriz à pesquisa, esta se tornaria inútil, mero ajuntamento de dados, sem "trabalho ativo de investigação". A perspectiva adotada por Willems impediria também a compreensão do processo de transformaçóes em curso:

O próprio tema escolhido pelo professor Willems é dialético por definição: "tradição e transição em uma cultura rural do Brasil” é o subtítulo do livro. No entanto, ele se mostra incapaz de por em evidência a dinâmica dos fatos que observa e julga analisar (idem, p. 26).
Tratar-se-ia, portanto, de método que conduz apenas à observação externa e superficial, sem sistematização alguma, sem teoria. Caio Prado Jr. propóe então outra visão de ciência, cujo ponto de partida seria sempre, "em qualquer pesquisa ou estudo, uma teoria, um sistema de ideias, sublinhando ainda o perigo de tais análises aparentemente neutras, mas potencialmente reacionárias" (idem, p. 28).

Já mencionei o debate entre Pierson, Willems e Florestan, no qual este reitera os termos de Caio Prado Jr., nas entrelinhas da polêmica. O mesmo ocorre com textos de Octávio Ianni (1961) e Maria Sylvia de Carvalho Franco (1963). Aludindo às transformações em curso no país e à superação da antiga civilização agrária, Ianni indica o fortalecimento das ciências sociais como forma racional de explicação da realidade, associada a tal contexto. Propóe então uma reflexão sobre a contribuição "proveniente dos centros norte-americanos". Depois de enumerar os estudos realizados, faz um balanço:

Para romper de maneira drástica com os ensaios histórico-sociais produzidos no passado, como se certos caracteres formais dessas obras devessem ser sumariamente abandonados com os métodos explicativos adotados, grande parte dos estudiosos formados pelas universidades e escolas criadas a partir de 1930 preferiu o que lhes foi apresentado como "científico", "positivo", "mais refinado", em contraposição ao que se lhes afigurava "especulativo" ou "pré-científico”. Desta maneira ganhou-se em precisão e rigor na observação e tratamento descritivo dos eventos, perdendo-se algumas vezes a riqueza e a desenvoltura no uso criador da inteligência (Ianni, 1961, p. 70).

Evidentemente o alvo não seria o conjunto da produção acadêmica, mas aquela que, conforme a passagem, insistia na descrição. $\mathrm{O}$ exemplo tomado em seguida é Cunha e, embo- 
ra sem fazer menção à resenha de Caio Prado, o tom da crítica é muito parecido, afirmando a incapacidade do autor de dar sentido às transformações descritas:

Mas para isso seria necessário lidar-se com uma outra concepção da realidade. Seria preciso abordar-se os fenômenos e processos tendo-se em vista uma concepção de totalidade que não admite nem um estado de equilíbrio nem uma distribuição harmônica das condiçóes e fatores (idem, p. 75).

Ianni aponta ainda a falta de critérios científicos na escolha das comunidades estudadas, isso por não haver em tais estudos a necessária reflexão teórica anterior, que definiria os processos a serem estudados e, consequentemente, os locais indicados. Enfim, ênfase na teoria e na análise histórica, ausentes nos "estudos de comunidades", o que também dá o tom ao texto "O estudo sociológico de comunidades", de Maria Sylvia de Carvalho Franco (1963).

Segundo a autora, o principal erro desses estudos seria a delimitação espacial necessária ao método herdado da sociologia americana de Chicago, através da qual se pretendia esgotar a realidade por meio de pesquisa empírica exaustiva, ampliada pela multiplicaçáo de estudos similares e pelo método comparativo.

A superação dessa perspectiva dar-se-ia pela sofisticação da teoria, que permitiria desprenderse do objeto espacialmente limitado para buscar a "descoberta de determinaçóes que fundamentalmente definem o sistema social" (idem, p. 31), sendo necessário o planejamento cuidadoso do trabalho "para desvendar os mecanismos essenciais de integração dos componentes estruturais e funcionais que são relevantes para os propósitos da pesquisa” (idem, p. 31). Assim:

fenômenos ocorridos em áreas que, de acordo com a delimitaçáo do âmbito de uma comuni- dade, não seriam levados em conta, podem ser incorporados à análise e à interpretação, desde que inscritos em situação histórico-social do mesmo tipo, visto como o critério para a escolha das situaçôes concretas a serem incluídas no estudo será a sua relevância tendo em vista as hipóteses específicas propostas (idem, p. 32).

A segunda dimensão analítica ausente seria a histórica, mas não restrita às determinaçóes específicas às comunidades estudadas, subordinadas a processos mais amplos, vigentes desde a colonização, cuja compreensão seria indispensável:

Nesse período, o fenômeno chave para se apreender o sentido das relaçóes sociais é o da díade senhor e escravo, sendo quase destituída de importância para os destinos da sociedade global, os problemas referentes aos habitantes de pequenas comunidades (idem, p. 36)

Isso nos leva à terceira dimensão de sua crítica, a ênfase no estudo dos setores da vida social que se referem às relaçóes comunitárias e não daqueles vinculados às relaçôes societárias. Tal abordagem limitaria as interpretaçóes aos aspectos estáveis da sociabilidade, excluindo "toda ideia de oposição e luta, e em certa medida, de estratificação e domínio" (idem, p. 37). A percepção dos conflitos estaria, assim, comprometida. Nesse sentido, Maria Sylvia propóe que a atenção do pesquisador esteja voltada para as tendências de transformação, típicas das relações societárias.

Antonio Candido e Gioconda Mussolini também criticaram os "estudos de comunidades”, mas doutra maneira. Veremos que ambos avaliaram a contribuição de tais trabalhos positivamente, embora indicassem problemas de método e de interpretação, a serem superados naquele momento.

Os artigos foram publicados nos Anais do XXXI Congresso Internacional dos Americanistas. 
Antonio Candido faz um panorama dos estudos até então realizados sobre o mundo rural no Brasil. Deste, entretanto, deixa entrever sua perspectiva sobre o assunto. Esta, aliás, já está presente no primeiro parágrafo do texto, quando reconhece a existência no Brasil duma "dualidade de civilização", aproximando-se de Euclides da Cunha (e de Jacques Lambert):

O desenvolvimento de novos valores, de uma mentalidade e concepção de vida novas vão marcar cada vez mais ao longo do século passado [XIX], e, sobretudo deste, uma dualidade de civilização em que se vê claramente um Brasil urbano distanciando-se mais e mais do velho Brasil rural e tradicional (Candido, 1955, p. 321).

Os "estudos de comunidades" seriam para ele, portanto, um passo decisivo para se apreender sociologicamente o universo social e cultural do homem pobre do campo, "representante típico" do mundo rústico brasileiro: "Seu representante típico não foi estudado e é com dificuldade que o conhecemos: refiro-me ao camponês livre, proprietário ou não, branco, ou mestiço, às vezes negro, fruto de longa aculturação e mestiçagem" (idem, p. 322).

Depois de referir-se à literatura regional e aos folcloristas, Antonio Candido passa a examinar os "estudos sistemáticos, desde a geografia até a sociologia e antropologia, estes voltados propriamente para a análise da organização social e da cultura”. Avalia então os trabalhos de Willems, Pierson e Wagley, afirmando-os como "os esforços mais notáveis para estudar em profundidade as sociedades rústicas do Brasil, ao menos no que respeita à investigação de campo e localizada" (idem, p. 326).

A passagem é significativa, pois apresenta o que o autor considera como avanço, a pesquisa empírica seriamente desenvolvida, e como erro, a ênfase exagerada na delimitação espacial e temporal dos trabalhos. O texto é finalizado com a crítica ao conceito de "comunidade", que seria indiscriminadamente usado e impreciso para caracterizar a realidade social complexa do mundo rural brasileiro. Sugere então o direcionamento das pesquisas para a análise do "bairro rural", para ele a forma elementar da sociabilidade do homem simples no Brasil rural, sem se descuidar das relaçóes do bairro com a sociedade abrangente. Afirma também a necessidade de realizarem-se pesquisas sobre estratificação social que possibilitassem melhor compreensão das relaçóes entre os diferentes estratos sociais. Finalmente conclui, antecipando um ponto radicalizado por Maria Sylvia, a ênfase nas relações societárias:

Eu me dispenso de indicar as questóes concretas em detalhe, que podem constituir objetos de pesquisa. É suficiente assinalar que estas devem colocar-se num plano essencialmente dinâmico e integrativo, já que os grupos brasileiros de cultura rústica vivem em sua maioria os diversos estágios de sua incorporação à cultura urbana e portanto da participação nos grandes problemas que ultrapassam seus limites tradicionais (idem, p. 332).

O texto de Gioconda Mussolini, "Persistência e mudança em sociedades de 'folk' no Brasil" (1955), revela a sutileza do pensamento da autora, cujo doutorado sobre o mundo caiçara não foi terminado. A análise incide inicialmente na distinção entre "zonas velhas" e "zonas novas" do povoamento para afirmar a necessidade de aprofundar-se a análise histórica, fundamental para a compreensão da evolução particular de cada regiáo e grupo, assim como de determinaçôes mais gerais. Reforça então a crítica de Foster a Redfield, enfatizando a relação sempre existente e fundamental da sociedade folk com a sociedade abrangente.

Em relação aos estudos sobre mudança social, a autora analisa a extensa gama de possibilidades de estruturação das formas de 
organização social e das relações entre sociedade e cultura, mostrando como não há um único sentido para a transformação das "sociedades folk", como suposto por Redfield, e sim alternativas complexas e indeterminadas. Mussolini reconhecia, entretanto, como Antonio Candido, uma uniformidade subjacente às variaçóes sociais e culturais do mundo rústico.

A análise da interpenetração entre as sociedades em contato é precisa e nuançada, conforme a passagem abaixo:

Contudo, não é demais insistir em que um estudo de comunidade deve ser sempre complementado pelo dos demais centros com que mantenha relaçóes a fim de verificar-se, quando for o caso, a natureza real dos contatos que seus membros mantêm com o centro urbano, de 'influência civilizadora'. Ousaríamos dizer que a heterogeneidade das cidades representa, de certo modo, a possibilidade de se manter a homogeneidade rural (Mussolini, 1955).

A clivagem decisiva no desenvolvimento dos estudos rurais na USP seria, contudo, de natureza política. Lembramos que a ELSP representava na ótica da USP um projeto conservador. Se nossa hipótese é correta, tal circunstância teria determinado a recepção dos "estudos de comunidades", criticados mesmo por aqueles que não estavam tão distantes de sua orientação teórica, como Gioconda Mussolini e Antonio Candido 5 . A primeira assistente de Willems na Cadeira de Antropologia realizou o mestrado na ELSP, sob orientação de Herbert Baldus, e participou da equipe de pesquisa recrutada para o trabalho de campo em Cunha. A antropóloga foi também co-autora (com Willems) de Buzio's Island (1952). Apesar disso, ao resenhar Cunha, em 1949, na Revista do Museu Paulista, a autora não rebateu a duríssima crítica (comentada anteriormente) de Caio Prado Jr. e avaliou o livro, se não negativamente, com sérias reservas:
Da falta, no texto, de outros espécimes que lhe sirvam de paralelos, provém a impressão de 'circularidade', de 'sistema fechado', comum em trabalhos deste gênero, e ademais, a dificuldade de quantificar, de destacar o 'grau' de organização ou desorganização, de estabilidade e instabilidade [...]. Quando ao finalizar o trabalho o prof. Willems procura interpretar a sociedade e a cultura locais em termos de estabilidade e instabilidade social, chegando a uma série de fatores responsáveis pela mudança, falta uma espécie de balanço que forneça a resultante do impacto destas duas ordens de fatores em confronto. [...] Ao trabalho sobre Cunha - excelente fonte de material e análises, ponto de referência para futuros estudos - falta, a nosso ver, uma certa interação entre as proposiçóes gerais que lhe serviram de base e os fatos particulares que ilustra, numa redefinição daquelas proposições, que impedisse a impressão de reificação de conceitos (Mussolini, 1949).

Também Antonio Candido fez questão de marcar, em Os parceiros do Rio Bonito (1964), a distância que o separava de tais estudos, ao criticar a imparcialidade que defendiam, afirmando que no seu trabalho procurava "localizar um aspecto da vida social [...] considerado não só como tema sociológico, mas também como problema social' (op. cit, p. 20).

A verdade é que a recepção de Cunha ficou bem aquém das expectativas de Emílio Willems. O livro foi também preterido na disputa do prêmio Fábio Prado (1948), conquistado por Organização Social dos Tupinambás, de Florestan Fernandes. Tais fatos refletem, em certa medida, a disputa entre as instituiçôes, pagando Willems um preço alto por identificar-se com a ELSP e com o projeto acadêmico de Donald Pierson. Em 1949, o antropólogo alemão aceitaria um convite da universidade americana de Vanderbilt, onde se aposentaria. 


\section{Notas}

1 Este texto foi preparado para uma apresentação oral durante o evento "Constituindo um Campo": estudos de comunidade e o desenvolvimento das Ciências Sociais no Brasil (1940-1960), realizado na FFLCH/USP. Agradeço à organização do evento pelo convite e pela revisão do texto.

2 Sobre a revista, ver Limongi (1987) e Jackson (2004).

3 O debate teórico e metodológico sobre o problema da estratificação social constituiu, como notou Mariza Corrêa, um marco decisivo no desenvolvimento das ciências sociais em São Paulo. Cf. "A antropologia no Brasil (1960-1980)", In: Miceli (1995).

4 Em prefácio ao livro Sociologia e Folclore - A dança de São Gonçalo num povoado baiano, de Maria Isaura Pereira de Queiroz (1958), Thales de Azevedo refere-se ao acordo Universidade de Columbia/estado da Bahia, nos seguintes termos:

"Ao ser estabelecida em janeiro de 1951, a Fundaçáo para o Desenvolvimento da Ciência na Bahia foi encarregada do cumprimento do convênio, firmado e em execução desde meados de 1949, entre o Governo do estado da Bahia, pelo seu Departamento de Educação, e a Columbia University, de N. York, pelo seu Departamento de Antropologia, para uma série de pesquisas socioculturais em comunidades típicas das várias regiôes geo-econômicas do estado em ordem à obtenção de conhecimentos que servissem de base ao planejamento da educação, da assistência médica e da administração, iniciativa do então Secretário de Educação e Saúde, Prof. Anísio Teixeira. Tornado realidade graças à alta compreensão do Governador Octávio Mangabeira, o convênio veio a corporificar-se no Programa de Pesquisas Sociais Estado da Bahia e Universidade de Columbia, sob a direçáo geral do autor de seu plano, prof. Charles Wagley, com a nossa colaboração como diretor regional, encarregado do cumprimento do acordo por parte do Governo baiano, e do Prof. L. A. Costa Pinto, como consultor. Das pesquisas de campo realizadas entre 1949 e 1953 por um grupo de antropologistas norte-americanos, auxiliados por estudantes brasileiros, conforme plano e métodos expostos na publicação Uma pesquisa sobre a vida social no Estado da Bahia, de C. Wagley, T. de Azevedo e L. A. Costa Pinto (1950) e nos artigos "Sobre métodos de campo no estudo de comunidade", de C. Wagley e T. de Azevedo (1951) e "Pesquisas sobre a Bahia", de L. A. Costa Pinto (1950), resultaram até o momento diversos artigos, comunicaçôes a reuniōes científicas e teses de doutorado; duas das últimas publicaram-se sob a forma de livro: Town and Country in Brazil, de Marvin Harris, estudo de comunidades do alto sertão, na antiga zona de mineração de ouro, e Village and Plantation Life in Northeastern Brazil, de Harry W. Hutchinson, sobre a organização social de usinas e fazendas do Recôncavo açucareiro; Rollie E. Poppino escreveu "Princess of the Sertão: a history of Feira de Santana" e Anthony Leeds, "Economic Cycles in Brazil: the persistence of a total-culture pattern", com base em investigação na zona cacaueira. Por solicitação do Departamento de Ciências Sociais da UNESCO e adotando planos estabelecidos em colaboração com o prof. Alfred Metraux, diretor do Programa de Tensóes daquela entidade, executaram-se pesquisas sobre relaçốes raciais, vindo a ser publicados os livros Race and Class in Rural Brazil, edição da UNESCO organizada por C. Wagley com a colaboração de M. Harris. H. W. Hutchinson e B. Zimmerman, e Les elites de couleur dans une ville brésilienne, de Thales de Azevedo, igualmente editada por aquele órgão das Naçóes Unidas, além de publicado em vernáculo pela Cia. Editora Nacional na série "Brasiliana"”. (In: Queiroz, 1958., p. 6).

Seria de grande interesse uma pesquisa comparativa sobre as obras produzidas nos dois casos. Aparentemente, o "ataque" da USP aos "estudos de comunidades" foi mais duro em relação aos trabalhos produzidos na ELSP, fato que reforçaria a dimensão institucional do debate. Essa impressão baseia-se em resenhas favoráveis, de autoria de Octávio Ianni e Fernando Henrique Cardoso, publicadas no Suplemento Literário, sobre os trabalhos de Marvin Harris, Town and Country in Brazil (1956), e de Harry W. Hutchinson, Village and Plantation Life in Northeastern Brazil (1957).

5 Não queremos dizer com isso que as críticas não tivessem fundamentos científicos, mas que ambos sublinharam as diferenças que os afastavam dessa perspectiva, também em função das disputas entre as instituiçôes. 


\section{Referências bibliográficas}

CANDIDO, Antonio, L'État actuel et les problèmes les plus importants des études sur les sociétés rurales du Brésil. Anais do $31^{\circ}$ Congresso Internacional de Americanistas, São Paulo, p. 321, 1955.

Os parceiros do rio Bonito. Rio de Janeiro: José Olympio, 1964.

CORRÊA, Mariza. A antropologia no Brasil (19601980). In: MICELI, Sérgio (org.), História das Ciências Sociais no Brasil [v.2], São Paulo: Sumaré, Idesp, Fapesp, 1995.

COSTA PINTO, Luiz de Aguiar. Pesquisas sobre a Bahia. Digesto Econômico, São Paulo, set., 1950.

FRANCO, Maria Sylvia Carvalho. O estudo sociológico de comunidades. Revista de Antropologia, v 11, n. 2, p. 31, 1963.

FERNANDES, Florestan. A análise sociológica das classes sociais. Revista Sociologia [Symposium sobre classes sociais], v. 10, n.2, 1948.

IANNI, Octavio. Estudo de comunidade e conhecimento científico. Revista de Antropologia, vol. 9, n. 1 e 2, 1961.

JACKSON, Luiz. A sociologia paulista nas revistas especializadas (1940-1965), Tempo Social, v.16, n.1, (2004).

LIMONGI, Fernando. Revista Sociologia: a ELSP e o desenvolvimento da sociologia em Sáo Paulo. In: Ca- derno IDESP, 1 (série: História das Ciências Sociais), 1987.

MUSSOLINI, Gioconda. Persistência e mudança em sociedades de 'folk' no Brasil. Anais do XXXI Congresso Internacional dos Americanistas, 1955.

Resenha de "Cunha". Revista do Museu Paulista, vol. III, p. 477-80, 1949.

NOGUEIRA, Oracy. Os estudos de comunidade no Brasil. Revista de Antropologia, vol. 3, n. 2, 1955.

PRADO JR, Caio. Métodos sociológicos. Fundamentos, n. 4, 1948.

QUEIROZ, Maria Isaura Pereira de. Sociologia e folclore: a dança de São Gonçalo num povoado baiano. Salvador, Programa de Pesquisas Sociais da Fundação para o Desenvolvimento da Ciência, 1, 1958.

WAGLEY, Charles. Estudos de comunidades no Brasil sob perspectiva nacional. Revista Sociologia, v. 16 n. 2, maio de 1954.

. e AZEVEDO, Thales. Sobre métodos de campo no estudo de comunidade. Revista do Museu Paulista, v. 4, p.227-237, 1950.

e COSTA

PINTO, Luiz de Aguiar. Uma pesquisa sobre a vida social no Estado da Bahia, Edição do Museu do Estado, n.11, 1950.

WILLEMS, Emílio Cunha. Tradição e transição em uma cultura rural do Brasil. São Paulo, Secretaria de Agricultura, 1947.

autor

Luiz Carlos Jackson

Professor do Departamento de Sociologia/USP

Doutor em Sociologia/USP

Recebido em 18/09/2009

Aceito para publicação em 18/09/2009 